\title{
Wistar rats with long-term streptozotocin-induced type 1 diabetes mellitus replicate the most relevant clinical, biochemical, and hematologic features of human diabetes
}

\section{Sobolanii Wistar cu diabet zaharat tip 1 indus cu streptozotocina reproduc cele mai relevante caracteristici clinice, biochimice si hematologice ale diabetului uman}

\author{
Alina Scridon ${ }^{1 *}$, Marcel Perian ${ }^{1}$, Alina Marginean ${ }^{1}$, Ciprian Fisca $^{1}$, Adriana \\ Vantu ${ }^{1}$, Doina Ghertescu ${ }^{1}$, Philippe Chevalier ${ }^{2}$, Razvan Constantin Serban ${ }^{1,3}$
}

1. University of Medicine and Pharmacy of Tirgu Mures; 2. Service de Rythmologie, Hospices Civils de Lyon, Hopital Louis Pradel, Bron Cedex 69500, France; 3. Emergency Institute for Cardiovascular Diseases and Transplantation Tirgu Mures, Romania

\begin{abstract}
Background: Experimental models are essential for clarifying the pathogenesis of diabetes mellitus (DM). We aimed to provide an exhaustive description of clinical, biochemical, and hematologic features of rats with streptozotocin (STZ)-induced DM.

Methods: Wistar rats were assigned to control $(n=14)$ or DM $(n=17)$ groups. DM was induced using STZ (60 $\mathrm{mg} / \mathrm{kg}$, i.p.). If STZ failed to induce DM, rats were reinjected with a similar STZ dose. Bodyweight, 24-h food and water intake were measured weekly during 28 weeks. At the end of the study lipid profile, kidney function, and complete blood count were assessed.

Results: STZ induced DM in 58.82\% of rats. The second STZ administration induced DM in $71.43 \%$ of the remaining rats. Diabetics presented progressive, but less significant bodyweight increase than controls, and higher food and water consumption. At the end of the study, diabetics presented higher white blood cells count, glucose, triglycerides, total and low-density lipoprotein cholesterol, and lower creatinine clearance than controls (all $p \leq 0.02)$. No significant difference was observed between diabetics injected once and those that were reinjected, in any of the studied parameters.

Conclusions: This study provides one of the longest follow-ups of rats with STZ-induced type 1 DM, demonstrating that the STZ-diabetic rat replicates the most relevant clinical, biochemical, and hematologic features of human diabetes. The present data also indicate, for the first time, that rats with initial unsuccessful STZ administration can be safely reinjected, with outcomes similar to those seen in rats receiving a single injection.
\end{abstract}

Keywords: experimental model; Wistar rats;long-term follow-up;streptozotocin;type 1 diabetes mellitus

*Corresponding author: Alina Scridon , University of Medicine and Pharmacy of Tirgu Mures Tirgu Mure, Romania, e-mail: alinascridon@gmail.com;alina.scridon@umftgm.ro 


\section{Rezumat}

Introducere: Modelele experimentale sunt esentiale pentru elucidarea patogenezei diabetului zaharat (DZ). Ne-am propus sa realizam o descriere exhaustiva a caracteristicilor clinice, biochimice si hematologice ale sobolanilor cu DZ indus cu streptozotocina (STZ).

Metode: Sobolanii Wistar au fost distribuiti in grupul control ( $n=14)$ sau DZ (n=17). DZ a fost indus cu STZ (60 mg/kg, i.p.). Daca STZ nu a indus DZ, sobolanii au fost reinjectati cu o doza similara de STZ. Masele corporale (MC) si consumul de hrana si apa/24h au fost evaluate saptamanal 28 de saptamani. La sfarsitul studiului s-au evaluat profilul lipidic, functia renala si hemoleucograma.

Rezultate: STZ a indus DZ la 58,82\% dintre sobolani. Reinjectarea a indus DZ la 71,53\% din restul sobolanilor. Diabeticii au prezentat o crestere progresiva, dar mai putin importanta a MC comparativ cu sobolanii control si un consum mai important de hrana si apa. La sfarsitul studiului diabeticii au prezentat niveluri mai ridicate ale leucocitelor, glicemiei, trigliceridelor, colesterolului total si LDL-colesterolului si un clearance de creatinina mai redus ( $p \leq 0,02)$. Nu s-a observat nici o diferenta intre diabeticii injectati o singura data si cei reinjectati pentru nici unul dintre parametrii evaluati.

Concluzii: Asigurand una dintre cele mai indelungate urmariri ale sobolanilor cu DZ indus cu STZ, acest studiu demonstreaza ca sobolanii diabetici reproduc cele mai relevante caracteristici clinice, biochimice si hematologice ale diabetului uman, dar si ca sobolanii cu injectare ineficienta de STZ pot fi reinjectati in siguranta, avand o evolutie similara cu a celor care au primit o singura administrare.

Cuvinte cheie: model experimental;sobolani Wistar;urmarire pe termen lung;streptozotocina;diabet zaharat tip 1

\section{Received: 10 ${ }^{\text {th }}$ May 2015; Accepted: $18^{\text {th }}$ July 2015; Published: $18^{\text {th }}$ August 2015}

\section{Introduction}

Diabetes mellitus (DM) represents a major global health concern, affecting more than $6 \%$ of the general population (1). Approximately $10 \%$ of all diabetic cases are represented by type 1 DM (2), condition characterized by deficient insulin production due to inflammatory infiltration and selective destruction of pancreatic $\beta$-cells (3). The presence of the disease imposes lifelong daily insulin treatment, which is partially effective, at best (4), whilst no efficient prophylactic methods have been identified so far (5).

Studies performed on experimental models are essential for clarifying the pathogenesis and progression of the disease. Streptozotocin (STZ), a cytotoxic glucose analogue that preferentially accumulates in pancreatic $\beta$-cells is one of the most effective diabetogenic chemicals (6). Administration of a single STZ dose of 50 to 65 $\mathrm{mg} / \mathrm{kg}$ of bodyweight results in selective toxic- ity to $\beta$-cells, inducing type $1 \mathrm{DM}$ in adult rats within 2 to 4 days, whilst severe ketosis does not develop even if insulin is not administered (7).

Despite the extensive volume of studies on STZ-induced DM in rats, the long-term course of this condition remains poorly described. Furthermore, little is known regarding success and mortality rates associated with this protocol, whereas no study has provided so far any information regarding the possibility of reinjecting the rats in which initial STZ administration failed to induce DM.

Accordingly, the purpose of our study was to provide exhaustive clinical, biochemical, and hematological characterization of the STZ-induced type $1 \mathrm{DM}$ model in rats over the longterm. Additionally, success and mortality rates associated with this protocol, as well as the outcomes of rats reinjected after initial unsuccessful STZ administration were also assessed. 


\section{Materials and methods}

\section{Animals and housing}

Thirty-two 6-week-old male Wistar rats $(177.88 \pm 4.01 \mathrm{~g})$ were purchased from the Cantacuzino Experimental Station (Bucharest, Romania). The rats were randomly assigned to control $(n=14)$ or DM $(n=18)$ groups.

All animals were allowed one week of accommodation prior to the beginning of the study, were housed individually in polycarbonate cages in a climate-controlled room $\left(21-24^{\circ} \mathrm{C}\right)$ with a 12-hour light/12-hour dark photoperiod, in an accredited animal facility and had free access to food and water.

All experiments were performed in compliance with the International Council for Laboratory Animal Science guidelines (Directive 2010/63/EU) and were approved by the local Ethics Committee.

\section{Induction of diabetes mellitus}

Bodyweight and 24-h food and water intake were monitored in baseline conditions from 7 weeks to 11 weeks of age, when rats assigned to the DM group were fasted for 12-h with free access to water and then injected intraperitoneally with STZ (60 mg/kg of bodyweight; Sigma-Aldrich, St Louis, MO) diluted in citrate-buffered saline (0.1 mol/1, pH 4.5; Sigma-Aldrich), as previously described (8). Immediately after STZ administration, rats were allowed free access to food and water. One rat in the DM group died during STZ injection and was excluded from any further analysis. Insulin was not administered. Control rats received a similar intraperitoneal volume of citrate buffer, without STZ.

Seven days later, STZ-treated rats were again subjected to 12-h of fasting and glucose levels were measured to confirm the induction of DM. In line with previous studies (8), rats were considered diabetics if plasma glucose exceeded $250 \mathrm{mg} / \mathrm{dl}$. Rats that did not comply with this request were injected again, with a similar dose of STZ, and glycemic levels were retested one week later.

For measuring glycemic levels, rats were anesthetized with Isoflurane and a small volume of blood was collected by making a transverse section through the long axis of the tail $2 \mathrm{~mm}$ from the tip. Glucose levels were measured using advanced biosensor technology with a clinical glucometer (SensoCard; Elektronika Kft., Budapest, Hungary) and commercially available test strips (SensoCard).

The general status of all rats was assessed daily, and bodyweights and 24-h food and water intake were measured weekly up to the age of 38 weeks.

\section{Noninvasive blood pressure and heart rate measurement}

Noninvasive systolic blood pressure measurement was performed by photopletismography on Isoflurane-anesthetized rats at 11 and 38 weeks of age, respectively.

A pneumatic tail cuff was placed proximally on the rat's tail and inflated/deflated using the PE-300 programmed electro-sphygmomanometer (Narco Bio-Systems Inc., Houston, TX). The photopletismography sensor was placed on the tail distally to the pneumatic cuff, with the infrared beam crossing the caudal artery. The cuff pressure signal was routed to Channel 1, whilst the phototransducer signals were routed to Channel 2 of a signal acquisition board (DT-301; Data Translation Inc., Marlboro, MA). An acquisition program developed in our laboratory using LabVIEW 8.20 software (National Instruments, Austin, TX) allowed the signal to be continuously recorded with a $16 \mathrm{kHz}$ sampling frequency and be stored on a hard disk. Two measurements were performed for each rat; the values used for between-groups comparisons correspond to the means of the two values. Heart rates were derived from the pressure waves' recordings. 
In five diabetics signal quality was inadequate for blood pressure measurement and additional vasodilation using a heating lamp had to be used to improve signal quality. Even so, blood pressure could not be measured in three diabetics, which were excluded from this analysis.

\section{Blood sampling and analysis}

At the end of the study all rats were anesthetized with Isoflurane and non-fasting glucose levels, systolic blood pressures and heart rates were measured as previously described. The abdominal cavity was opened, the aorta was cannulated, and blood was collected in a vacutainer containing ethylenediaminetetraacetic acid.

Complete blood count was performed using the direct current detection method (Sysmex XP-300 Automated Hematology Analyzer; Sysmex Corporation, Japan). Total, high-density lipoprotein (HDL) and low-density lipoprotein (LDL) cholesterol, triglycerides, and uric acid levels were measured by enzymatic colorimetric methods using automatic analyzers (Cobas 6000 analyzer series; Roche Diagnostics, Switzerland and Dimension RxL Max; Siemens Healthcare Global, U.S.A.). Plasma creatinine was measured using a buffered kinetic Jaffe reaction without deproteinization. Creatinine clearance was calculated using a previously validated equation for rats (9), as follows:

Creatinine clearance $(\mathrm{ml} / \mathrm{min})=220 \mu \mathrm{mol} /$ $\mathrm{min} / \mathrm{kg}$ of bodyweight $\mathrm{x}$ bodyweight $(\mathrm{kg}) \mathrm{x}$ plasma creatinine $(\mu \mathrm{mol} / 1)^{-1}$.

\section{Statistics}

Continuous variables were expressed as means \pm SEM and were compared using the Mann-Whitney $U$ test. Categorical data were expressed as a number (percentage) and were compared using Fisher's exact test. Differences within the same group were tested for significance with the Wilcoxon signed-rank test. Correlations were ascertained with Spearman's correlation method.
A two-tailed p-value of less than 0.05 was considered statistically significant. Statistical analysis was undertaken using GraphPad Prism software (GraphPad Software; San Diego, CA).

\section{Results}

\section{Success rates of streptozotocin administration and mortality rates among diabetic rats}

At the beginning of the study, there was no significant difference in plasma glucose between rats randomized to control and DM groups $(\mathrm{p}=0.13)$. STZ successfully induced DM in $10(58.82 \%)$ rats (mean fasting glucose levels $358.5 \pm 45.1 \mathrm{mg} / \mathrm{dl}$ ). The remaining 7 rats were reinjected with a similar dose of STZ. This second administration successfully induced DM in $5(71.43 \%)$ rats (mean glucose levels $352.4 \pm 17.4$ $\mathrm{mg} / \mathrm{dl})$, but failed to induce diabetes in 2 rats, which were excluded from any further analysis. There was no significant difference between the glycemic levels of rats that underwent one versus two $\mathrm{STZ}$ administrations $(\mathrm{p}=0.57)$. The overall success rate of STZ administration was $88.24 \%$.

None of the controls died during the study, whilst 4 deaths occurred among the 17 diabetics $(23.5 \%)$. No deaths were recorded during the period immediately following STZ administration. The mean STZ administration-to-death interval was $18.5 \pm 2.9$ weeks. Mortality rates were similar in rats subjected to one versus two STZ administrations $(p=1.00)$. Moreover, among the reinjected rats, the two deaths occurred in rats with unsuccessful administration.

\section{Long-term evolutions of bodyweight, food and water intake in diabetic rats}

Up to the age of 11 weeks, when rats in the DM group were injected with STZ, all rats presented a progressive increase in bodyweight (Figure 1, A), food (Figure 1, B) and water (Fig- 
A

OControl Diabetes mellitus

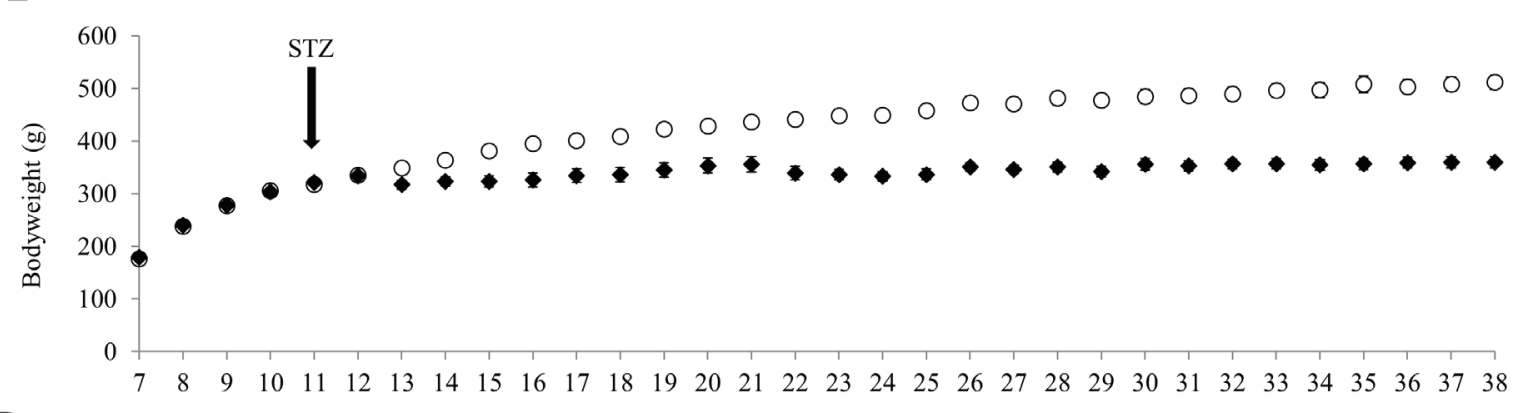

B

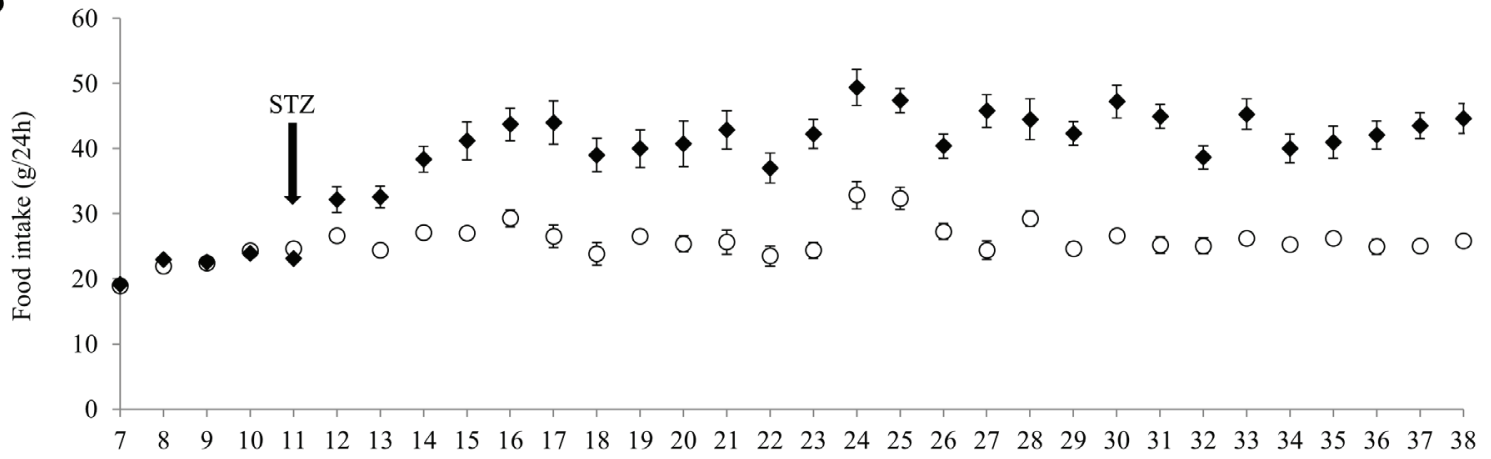

C

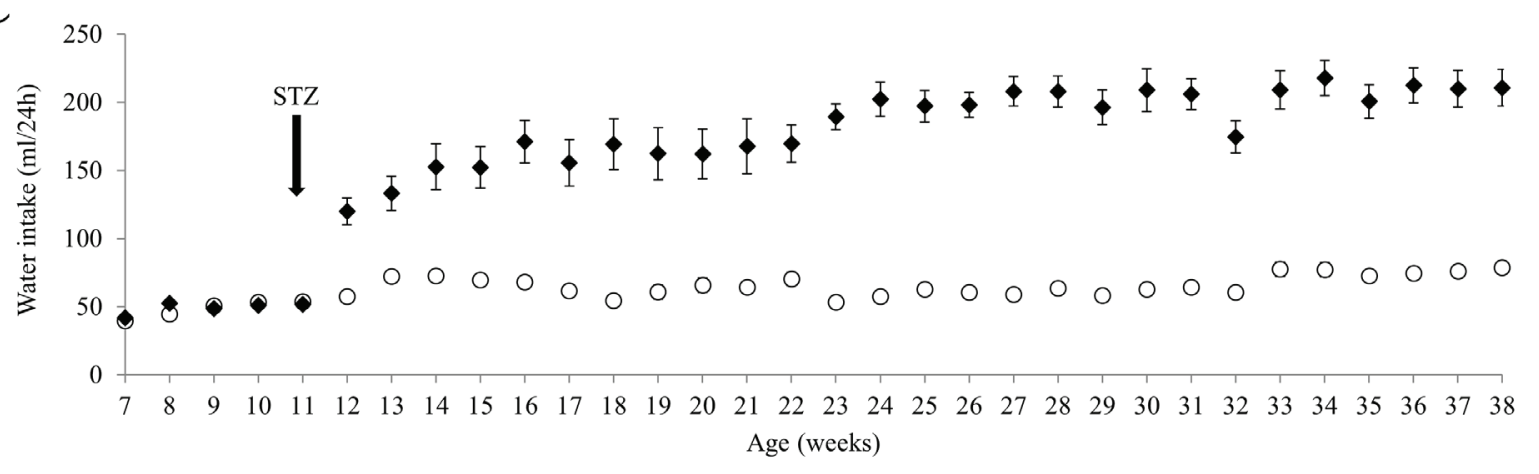

Data are expressed as means \pm SEM. The arrows indicate the moment of streptozotocin (STZ) administration.

Figure 1. Bodyweight (A) 24-h food (B) and water (C) intake evolutions in control and diabetic rats throughout the study (7 weeks to 38 weeks of age).

ure $1, \mathrm{C}$ ) intake. During these 4 weeks there was no significant difference in any of these parameters between the two groups (all $\mathrm{p}>0.05$ ).

In controls, the progressive increase in bodyweight continued throughout the study, with a significant positive correlation between bodyweight and age (Spearman $\mathrm{r}=0.71, \mathrm{p}<0.001$ ). In diabetics, a progressive increase in bodyweight was also observed with advancing age (Spearman $\mathrm{r}=0.30, \mathrm{p}<0.001)$. However, this increase was significantly less relevant than that seen in controls (Table I). Differences in bodyweight between the two groups started to emerge two weeks after STZ administration and remained 
Table I. Bodyweight and 24-h food and water intake evolutions in control and diabetic rats.

\begin{tabular}{lccc}
\hline Parameter & Control & Diabetes mellitus & p-value \\
\hline Initial bodyweight $(\mathrm{g})$ & $176.21 \pm 6.13$ & $179.17 \pm 5.43$ & 0.62 \\
\hline Initial bodyweight gain $(\mathrm{g})$ & $131.14 \pm 4.06$ & $141.94 \pm 6.18$ & 0.49 \\
\hline Long-term bodyweight gain $(\mathrm{g})$ & $204.07 \pm 9.45$ & $43.54 \pm 7.29$ & $<0.001$ \\
\hline Initial food intake $(\mathrm{g} / 24 \mathrm{~h})$ & $18.96 \pm 0.16$ & $19.08 \pm 0.05$ & 0.11 \\
\hline Food intake at 38 weeks of age $(\mathrm{g} / 24 \mathrm{~h})$ & $25.86 \pm 0.88$ & $44.64 \pm 2.31$ & $<0.001$ \\
\hline Initial water intake $(\mathrm{ml} / 24 \mathrm{~h})$ & $39.46 \pm 0.62$ & $40.31 \pm 0.43$ & 0.15 \\
\hline Water intake at 38 weeks of age $(\mathrm{ml} / 24 \mathrm{~h})$ & $78.57 \pm 2.43$ & $210.71 \pm 13.55$ & $<0.001$ \\
\hline $\begin{array}{l}\text { Initial bodyweight and food and water intake refer to the values measured at the age of 7 weeks in rats from the control (n=14) and diabetes mellitus (n=18) groups. Initial bodyweight gain } \\
\text { refers to the increase in bodyweight between 7 and 11 weeks of age in rats from the control (n=14) and diabetes mellitus (n=18) groups. Long-term bodyweight gain refers to the increase in } \\
\text { bodyweight between 11 and 38 weeks of age in control (n=14) and diabetic }(\mathrm{n}=13) \text { rats. } \\
\text { Data are expressed as means } \pm \text { SEM. p-values refer to comparisons between groups using the Mann-Whitney U test. }\end{array}$ &
\end{tabular}

significant throughout the study, with the highest difference being observed at the end of the study (511.43 $\pm 13.54 \mathrm{~g}$ in controls versus $365.46 \pm 10.03$ $\mathrm{g}$ in diabetics, $\mathrm{p}<0.001)$.

As expected, food and water intake were significantly higher in diabetics compared to controls (Figure 1, B and C). Differences in food and water intake between the two groups already became relevant one week after STZ administration and remained important throughout the study (Table I). When food and water consumption were expressed as a ratio to bodyweight, the differences between the two groups were even more important (food intake 50.68 \pm 1.45 $\mathrm{mg} / \mathrm{kg}$ of bodyweight $/ 24-\mathrm{h}$ in controls versus $120.82 \pm 6.13 \mathrm{mg} / \mathrm{kg}$ of bodyweight $/ 24-\mathrm{h}$ in diabetics, $\mathrm{p}<0.001$; water intake $155.33 \pm 6.93$ $\mathrm{ml} / \mathrm{kg}$ of bodyweight $/ 24-\mathrm{h}$ in controls versus $563.05 \pm 45.64 \mathrm{ml} / \mathrm{kg}$ of bodyweight $/ 24-\mathrm{h}$ in diabetics, $\mathrm{p}<0.001$ at 38 weeks of age).

Significant phenotypic differences were also observed between controls and diabetics. Whilst controls presented a white velvet coat and pink tails throughout the study, in diabetics the white velvet progressively turned into pink-grey, particularly behind the head and in the lower part

Table II. Bodyweight, 24-h food and water intake, systolic blood pressure, heart rate, biochemical and hematological parameters measured at the end of the study (38 weeks of age) in diabetic rats that received only one injection of streptozotocin versus those that were injected twice.

\begin{tabular}{|c|c|c|c|}
\hline Parameter & $\begin{array}{c}\text { Diabetes mellitus } \\
1 \mathrm{STZ}(\mathrm{n}=\mathbf{8})\end{array}$ & $\begin{array}{c}\text { Diabetes mellitus } \\
2 \text { STZ }(n=5)\end{array}$ & p-value \\
\hline Bodyweight (g) & $377.63 \pm 10.80$ & $346.00 \pm 17.47$ & 0.19 \\
\hline Food intake (g/24h) & $47.25 \pm 3.13$ & $39.20 \pm 3.02$ & 0.16 \\
\hline Water intake $(\mathrm{ml} / 24 \mathrm{~h})$ & $215.63 \pm 16.99$ & $190.00 \pm 23.18$ & 0.42 \\
\hline Systolic blood pressure $(\mathrm{mmHg})^{*}$ & $137.20 \pm 6.56$ & $130.20 \pm 1.65$ & 0.19 \\
\hline Heart rate $(\mathrm{bpm})^{*}$ & $286.43 \pm 11.73$ & $279.40 \pm 10.18$ & 0.68 \\
\hline Non-fasting plasma glucose $(\mathrm{mg} / \mathrm{dl})$ & $521.63 \pm 40.75$ & $489.20 \pm 32.59$ & 1.00 \\
\hline Total cholesterol $(\mathrm{mg} / \mathrm{dl})$ & $138.23 \pm 11.15$ & $135.32 \pm 24.40$ & 0.83 \\
\hline LDL-cholesterol (mg/dl) & $19.40 \pm 1.36$ & $18.29 \pm 2.85$ & 0.33 \\
\hline HDL-cholesterol (mg/dl) & $75.82 \pm 3.93$ & $70.53 \pm 4.47$ & 0.53 \\
\hline Triglycerides $(\mathrm{mg} / \mathrm{dl})$ & $423.16 \pm 77.28$ & $431.04 \pm 141.42$ & 0.94 \\
\hline Uric acid (mg/dl) & $0.51 \pm 0.25$ & $0.48 \pm 0.16$ & 0.66 \\
\hline Plasma creatinine $(\mu \mathrm{mol} / \mathrm{l})$ & $46.08 \pm 2.92$ & $44.20 \pm 2.89$ & 0.94 \\
\hline Creatinine clearance $(\mathrm{ml} / \mathrm{min})$ & $1.77 \pm 0.13$ & $1.71 \pm 0.20$ & 0.72 \\
\hline $\mathrm{WBC}\left(\times 10^{3} / \mathrm{mm}^{3}\right)$ & $4.73 \pm 0.83$ & $4.33 \pm 0.61$ & 0.70 \\
\hline $\mathrm{RBC}\left(\mathrm{x} 10^{6} / \mathrm{mm}^{3}\right)$ & $8.14 \pm 0.51$ & $8.07 \pm 0.29$ & 0.53 \\
\hline PLT $\left(\times 10^{6} / \mathrm{mm}^{3}\right)$ & $0.77 \pm 0.06$ & $0.76 \pm 0.26$ & 1.00 \\
\hline
\end{tabular}


of the body, and the tail became darker in color and stained.

At the end of the study, there were no significant differences in bodyweight, food or water intake between the diabetics that received only one STZ injection and those that were injected twice (Table II).

\section{Blood pressure and heart rate in diabetic rats}

At the beginning of the study, controls and diabetics presented similar systolic blood pressures (Figure 2, A) and heart rates (Figure 2, B).

Among controls, a significant increase in both systolic blood pressure and heart rate was observed with advancing age, whilst no such differences were observed among diabetics. At 38 weeks of age, there was no significant difference in systolic blood pressure between controls and diabetics $(p=0.15)$, but diabetics were significantly more bradycardic (Figure 2, B). Again, there was no significant difference in systolic blood pressures or heart rates between the diabetics that received only one STZ injection and those that were injected twice (Table II).

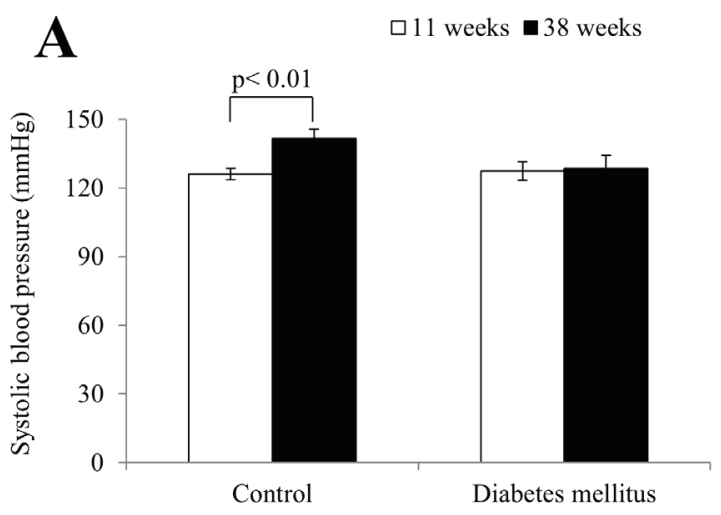

\section{Biochemical and hematological parame- ters in diabetic rats}

At the end of the study, non-fasting glucose levels were significantly higher in diabetics compared to controls (Table III). Similarly, diabetics presented significantly higher triglycerides, total and LDL-cholesterol, whilst there was no significant difference in HDL-cholesterol, uric acid or creatinine levels between the two groups. However, when creatinine clearance was calculated, diabetics presented significantly lower creatinine clearance than controls (Table III). As expected, HDL was significantly higher than LDL-cholesterol in both controls and diabetics (both $\mathrm{p}<0.001$ ).

Additionally, a significant increase in white blood cells (WBC) count was observed in diabetics compared to controls, whereas there was no significant difference in the number of red blood cells or platelets between the two groups (Table 3).

Again, there was no significant difference in any of the studied biochemical or hematological parameters between the diabetics that received only one STZ injection and those that were injected twice (Table II).

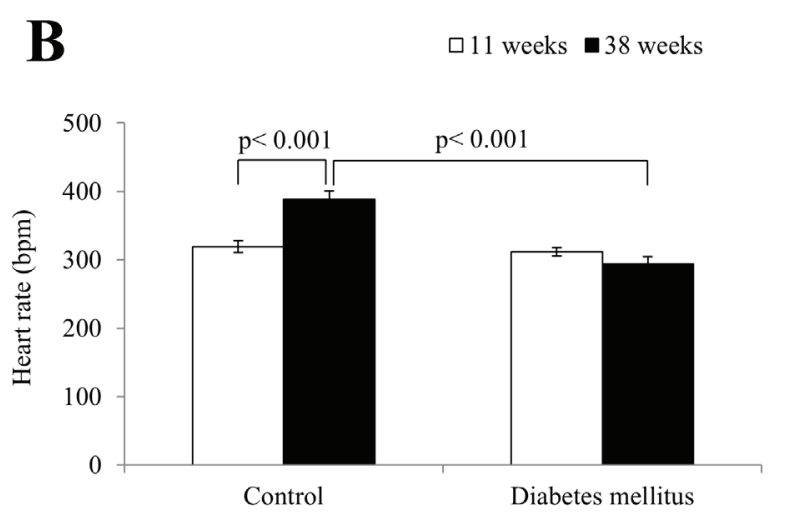

Data are expressed as means \pm SEM. p-values refer to comparisons between 11-week-old and 38-week-old control rats using the Wilcoxon matched-pairs signed-rank test, and between 38-week-old control and age-matched diabetic rats using the Mann-Whitney U test, respectively. Figure 2. Systolic blood pressure $(A)$ and heart rate $(B)$ values in control and diabetic rats at 11 weeks and 38 weeks of age, respectively. 
Table 3. Biochemical and hematological parameters measured at the end of the study (38 weeks of age) in control and diabetic rats.

\begin{tabular}{lccc}
\hline Parameter & $\begin{array}{c}\text { Control } \\
(\mathbf{n}=\mathbf{1 4})\end{array}$ & $\begin{array}{c}\text { Diabetes mellitus } \\
(\mathbf{n = 1 3})\end{array}$ & p-value \\
\hline Biochemical parameters & & & \\
\hline Non-fasting plasma glucose $(\mathrm{mg} / \mathrm{dl})$ & $117.29 \pm 3.25$ & $509.16 \pm 27.44$ & $<0.001$ \\
\hline Total cholesterol $(\mathrm{mg} / \mathrm{dl})$ & $87.85 \pm 3.39$ & $137.11 \pm 11.01$ & $<0.001$ \\
\hline LDL-cholesterol $(\mathrm{mg} / \mathrm{dl})$ & $14.36 \pm 0.76$ & $18.75 \pm 1.70$ & 0.02 \\
\hline HDL-cholesterol $(\mathrm{mg} / \mathrm{dl})$ & $68.27 \pm 3.52$ & $72.73 \pm 3.05$ & 0.36 \\
\hline Triglycerides $(\mathrm{mg} / \mathrm{dl})$ & $68.59 \pm 7.43$ & $426.19 \pm 68.62$ & $<0.001$ \\
\hline Uric acid $(\mathrm{mg} / \mathrm{dl})$ & $0.89 \pm 0.21$ & $0.50 \pm 0.16$ & 0.09 \\
\hline Plasma creatinine $(\mu \mathrm{mol} / \mathrm{l})$ & $41.74 \pm 1.74$ & $45.36 \pm 2.05$ & 0.13 \\
\hline Creatinine clearance $(\mathrm{ml} / \mathrm{min})$ & $2.75 \pm 0.10$ & $1.75 \pm 0.11$ & $<0.001$ \\
\hline Hematological parameters & & & 0.02 \\
\hline WBC $\left(\times 10^{3} / \mathrm{mm}^{3}\right)$ & $3.06 \pm 0.38$ & $4.53 \pm 0.49$ & 0.10 \\
\hline RBC $\left(\mathrm{x} \mathrm{10} / \mathrm{mm}^{3}\right)$ & $8.01 \pm 0.11$ & $8.10 \pm 0.27$ & 0.07 \\
\hline PLT $\left(\mathrm{x} 10^{6} / \mathrm{mm}^{3}\right)$ & $0.85 \pm 0.29$ & $0.76 \pm 0.26$ & \\
\hline
\end{tabular}

HDL - high-density lipoprotein; LDL - low-density lipoprotein; PLT - platelets; RBC - red blood cells; WBC - white blood cells

Data are expressed as means \pm SEM. p-values refer to comparisons between groups using the Mann-Whitney U test.

Among diabetics, glycemic levels were significantly positively correlated with water intake (Spearman $\mathrm{r}=0.57, \mathrm{p}=0.04$ ) and plasma creatinine (Spearman $\mathrm{r}=0.78, \mathrm{p}<0.01$ ) and significantly negatively correlated with creatinine clearance (Spearman $\mathrm{r}=-0.68, \mathrm{p}<0.01$ ), whilst no significant correlation was found between any of the studied parameters among controls.

\section{Discussions}

Type 1 DM leads not only to an important decrease in the quality of life, but also to substantial morbidity and mortality. Meanwhile, daily insulin treatment, mandatory in these patients, is only partially effective in preventing DM-related complications. These epidemiological data justify the need for developing experimental models that faithfully mimic the human condition.

STZ, a broad spectrum antimicrobial and antineoplastic agent acts as a potent cytotoxic glucose analogue, altering DNA fragments and causing pancreatic $\beta$-cells destruction, deprivation of insulin and type 1 DM (10). The ability of STZ to induce DM has been attributed to its specific chemical properties, particularly the ability of its methylnitrosourea fragment to induce DNA fragmentation, whilst its specificity for pancreatic $\beta$-cells is mainly due to its selective uptake by the $\beta$-cells via the GLUT2 glucose transporter and the consequent intracellular drug accumulation (11).

Previous studies on STZ-induced type 1 DM in rats have provided valuable insights into the short-term progression of this condition. However, since the study of long-term DM complications requires much longer follow-ups (7), a detailed description of the course of this condition over the long-term is of great interest. This approach becomes more important when considering that some animals appear to return to normoglycemic levels even after an initial period of hyperglycemia (12).

Although some studies have indeed assessed rats with STZ-induced type 1 DM over longer intervals of time (7), our study provides one of the longest and most detailed follow-ups of this model.

The streptozotocin-induced type 1 diabetes mellitus model in rats associates low long-term mortality rates and lack of early mortality

In the study of Wei et al., success rates of inducing DM, defined as a blood glucose $\geq 15 \mathrm{mM}$ 
and a water intake $>100 \mathrm{ml} / 24$-h seven days after STZ administration, were approximately $90 \%$ (7), considerably higher than the $58.82 \%$ found in our study. This difference may be related to the higher STZ dose and to the fact that the drug was administered intravenously in that study. However, when rats receiving a single STZ injection and those that were reinjected after initial unsuccessful administration were taken together, the overall success rates in our study raised to $88.24 \%$. Meanwhile, in our study mortality rates were considerably lower than those reported by Wei et al. (23.5\% versus $48 \%$ ) over a shorter, $24-$ week follow-up period (7). Taken together, these results support the role of the STZ dose and route of administration in influencing success and mortality rates, and suggest that STZ readministration in rats in which STZ initially failed to induce DM may be a good strategy to increase success rates without increasing mortality. Using a protocol similar to ours, Bahey et al. reported success rates closer to ours, STZ successfully inducing DM in 32 out of the 42 injected rats (8).

Interestingly, whilst most studies reported significant mortality rates in the days following STZ administration, this was not the case in our study. In fact, in our study, the first death was recorded 12 weeks after $\mathrm{STZ}$ administration. The high mortality rates following STZ administration have been linked to the characteristic triphasic effect of STZ (13). After an initial hyperglycemic phase, starting one hour after STZ administration and usually lasting $2 \mathrm{~h}$ to $4 \mathrm{~h}$, caused by inhibition of insulin secretion and sudden breakdown of liver glycogen, a second phase, of severe hypoglycemia, occurs due to flooding of the circulatory blood by the insulin released from the pancreas as a result of STZ-induced secretory granule and cell membrane rupture. Finally, permanent hyperglycemia sets in. The second phase, of severe hypoglycemia, was incriminated in the early deaths recorded following STZ administration. This hypothesis is further supported by the fact that administration of $5 \%$ dextrose efficiently prevented these early deaths (14). However, our results suggest that early free access to food may be just as effective in preventing early mortalities.

\section{Streptozotocin reinjection in rats with initial unsuccessful administration is safe and effective}

Our study is the first to demonstrate that STZ reinjection in rats with initial unsuccessful administration is safe and efficient, associating high success rates and similar mortality with that seen in rats receiving a single STZ injection. Furthermore, these rats displayed similar bodyweight, food and water intake evolutions to those of rats submitted to a single STZ administration. Also, there was no significant difference in systolic blood pressure, heart rate, or in any of the studied biochemical or hematological parameters between the two diabetic subgroups. Since long-term studies can be significantly hampered by loss of animals due to ineffective drug administration, the fact that these rats can be reinjected with STZ with no change in animals' outcomes may be of great procedural importance.

\section{Rats with streptozotocin-induced diabetes mellitus display a clinical phenotype simi- lar to that seen in diabetic patients}

Similarly to controls, diabetics displayed a progressive, but significantly less expressed increase in bodyweight over the long-term. This appears to contradict previous studies reporting decreased bodyweight with advancing age in diabetics $(14,15)$. However, in these latter studies, the follow-up period was significantly shorter. Indeed, an initial decrease in bodyweight could also be observed in our diabetic rats (Figure 1, A), although this decrease was not statistically significant. Moreover, in other long-term studies on STZ-diabetic rats, changes in bodyweight were similar to ours, demonstrating a progres- 
sive, but less significant increase compared to controls (16). As expected, diabetics also displayed significantly increased food and water consumption. Taken together, these results support the ability of the Wistar rat with STZ-induced DM to mimic many of the clinical signs of type $1 \mathrm{DM}$ seen in human patients.

\section{Rats with streptozotocin-induced diabetes mellitus display biochemical and hema- tological profiles similar to those seen in diabetic patients}

Similarly to what is commonly seen in type 1 diabetic patients, STZ-diabetic rats presented significant dyslipidemia, with a more prominent increase in triglycerides than in total cholesterol. Furthermore, whilst diabetics presented significantly increased LDL-cholesterol, HDL-cholesterol was similar between the two studied groups. Similar results have already been reported in type $1 \mathrm{DM}$ patients. However, it appears that these patients are likely to present significant changes in the composition of HDL particles, leading to an increased risk of new-onset cardiovascular diseases (17).

Additionally, significant kidney dysfunction was also observed, as demonstrated by the lower creatinine clearance in diabetics compared to controls, although there was no significant difference in plasma creatinine between the two groups. Finally, similarly to what is commonly seen in diabetic patients, STZ-diabetic rats also presented systemic inflammation, as demonstrated by the increased WBC count.

\section{Blood pressure and heart rate changes in diabetic rats}

Blood pressure and heart rate analysis demonstrated that although there was no significant difference in systolic blood pressure between non-diabetic and diabetic rats, the latter were significantly more bradycardic, as already reported in previous studies (18). However, our study demonstrates that the lower heart rates seen in diabetics were not due to an actual bradycardization of these rats, in which the heart rates were not significantly different than those recorded prior to $\mathrm{STZ}$ administration, but rather to a lack of increase in heart rate as that seen in controls. The different response in heart rate seen in diabetics may betray autonomic imbalance with predominance of parasympathetic nervous system activity $(19,20)$, in an attempt to correct the characteristic chronic hypoinsulinemia by compensatory growth and function of pancreatic islets, as suggested by Kiba et al. (21).

Surprisingly, whilst in controls systolic blood pressure increased with advancing age, this was not the case in diabetics, suggesting that the STZ-diabetic rat might not reproduce all abnormalities seen in human DM. Similarly, after 24 weeks of follow-up, using non-invasive blood pressure measurement, Wei et al. also found no significant difference in blood pressures of STZ-diabetic rats compared to controls (7). However, it is of note that whereas in all controls the blood pressure could be easily assessed, in five diabetics signal quality was inadequate for blood pressure measurement, and in three diabetics the signal remained inadequate even after additional vasodilation. These results suggest that diabetic rats may present peripheral artery disease causing significant impairment in peripheral blood flow. The significant dyslipidemia observed in these rats may play a significant role in this regard, although the presence of mediocalcinosis, commonly seen in diabetic patients, cannot be excluded. Indeed, whilst studies using non-invasive blood pressure measurement consistently reported no changes in blood pressure in diabetic rats, invasive measurement by arterial catheterization seems to confirm the presence of arterial hypertension (18). Since invasive blood pressure measurement was not performed in the present study, this hypothesis remains to be confirmed. 


\section{Potential limitations}

The fact that other parameters known to be affected in the presence of DM, such as urine output, plasma glycosylated hemoglobin levels or insulinemia were not assessed in the present study could be regarded as a potential limitation. Also, histopathological analysis of the pancreas and of a number of other tissues known to be affected by DM would have been of interest. However, many of these parameters have already been assessed in previous experimental studies. Furthermore, the present study was not designed to assess specific DM-related complications, but to provide an exhaustive description of the STZ-induced type $1 \mathrm{DM}$ model in rats. Further studies designed to assess specific DM-related changes will be of interest.

\section{Conclusions}

This study provides one of the longest and most detailed follow-ups of the most widely used experimental model of type $1 \mathrm{DM}$ and demonstrates that intraperitoneal administration of a 60 $\mathrm{mg} / \mathrm{kg}$ of bodyweight STZ dose is associated with low mortality rates. We also demonstrated, for the first time, that animals with initial unsuccessful STZ administration can be safely reinjected, with no change in animals' outcomes compared to rats receiving a single STZ injection. Taken together, our results support the usefulness of the STZ-diabetic rat as a model that reliably replicates many of the major clinical, biochemical, and hematologic features of type 1 human DM, but also the most relevant DM-related complications, including dyslipidemia, kidney dysfunction, systemic inflammation, and possibly autonomic imbalance and peripheral artery disease.

\section{Acknowledgments}

This work was supported by the University of Medicine and Pharmacy of Tîrgu Mureș Research Grant number 16/11.12.2013.
Abreviations
$\mathrm{DM}=$ diabetes mellitus
HDL $=$ high-density lipoprotein
$\mathrm{LDL}=$ low-density lipoprotein
PLT $=$ platelets
$\mathrm{RBC}=$ red blood cells
$\mathrm{STZ}=$ streptozotocin
$\mathrm{WBC}=$ white blood cells

\section{References}

1. Shaw JE, Sicree RA, Zimmet PZ. Global estimates of the prevalence of diabetes for 2010 and 2030. Diabetes Res Clin Pract. 2010 Jan;87(1):4-14. DOI: 10.1016/j. diabres.2009.10.007

2. Green A, Patterson CC; EURODIAB TIGER Study Group. Europe and Diabetes. Trends in the incidence of childhood-onset diabetes in Europe 1989-1998. Diabetologia. 2001 Oct;44(Suppl 3):B3-8. DOI: 10.1007/ PL00002950

3. Redondo MJ, Yu L, Hawa M, Mackenzie T, Pyke DA, Eisenbarth GS, et al. Heterogeneity of type I diabetes: Analysis of monozygotic twins in Great Britain and the United States. Diabetologia. 2001 Mar;44(3):354-62. DOI: $10.1007 / \mathrm{s} 001250051626$

4. Atkinson M, Eisenbarth G. Type 1 diabetes: new perspectives on disease pathogenesis and treatment. Lancet. 2001 Jul;358(9277):221-9. DOI: 10.1016/S01406736(01)05415-0

5. The Diabetes Prevention Trial-Type 1 Study Group. Effects of insulin in relatives of patients with type 1 diabetes mellitus. N Engl J Med. 2002 May;346(22):168591. DOI: $10.1056 /$ NEJMoa012350

6. Lenze S. The mechanisms of alloxan- and streptozotocin-induced diabetes. Diabetologia. 2008 Feb;51(2):216-26. DOI: 10.1007/s00125-007-0886-7

7. Wei M, Ong L, Smith MT, Ross FB, Schmid K, Hoey AJ, et al. The streptozotocin-diabetic rat as a model of the chronic complications of human diabetes. Heart Lung Circ. 2003;12(1):44-50. DOI: 10.1046/j.14442892.2003.00160.x

8. Bahey NG, Soliman GM, El-Deeb TA, El-Drieny EA. Influence of insulin and testosterone on diabetic rat ventral prostate: Histological, morphometric and immunohistochemical study. Journal of Microscopy and Ultrastructure. 2014;2(3):151-60. DOI: 10.1016/j. 
jmau.2014.06.002

9. Moorhead KT, Hill JV, Chase JG, Hann CE, Scotter JM, Storer MK, et al. Modelling acute renal failure using blood and breath biomarkers in rats. Comput Methods Programs Biomed. 2011 Feb;101(2):173-82. DOI: 10.1016/j.cmpb.2010.07.010

10. Boroujeni NB, Hashemi SM, Khaki Z, Soleimani M. The reversal of hyperglycemia after transplantation of mouse embryonic stem cells induced into early hepatocyte-like cells in streptozotocin-induced diabetic mice. Tissue Cell. 2011 Apr;43(2):75-82. DOI: 10.1016/j. tice.2010.12.002

11. Elsner M, Guldbakke B, Tiedge M, Munday R, Lenzen S. Relative importance of transport and alkylation for pancreatic beta-cell toxicity of streptozotocin. Diabetologia. 2000 Dec;43(12):1528-33. DOI: 10.1007/ s001250051564

12. Eleazu CO, Eleazu KC, Chukwuma S, Essien UN. Review of the mechanism of cell death resulting from streptozotocin challenge in experimental animals, its practical use and potential risk to humans. J Diabetes Metab Disord. 2013 Dec;12(1):60. DOI: 10.1186/22516581-12-60

13. Junod A, Lambert AE, Orci L, Pictet R, Gonet AE, Renold AE. Studies of the diabetogenic action of streptozotocin. Proc Soc Exp Biol Med. 1967 Oct;126(1):2015. DOI: 10.3181/00379727-126-32401

14. Huang M, Gao L, Yang L, Lin F, Lei H. Abnormalities in the brain of streptozotocin-induced type 1 diabetic rats revealed by diffusion tensor imaging. Neuroimage Clin. 2012 Sep;1(1):57-65. DOI: 10.1016/j. nicl.2012.09.004

15. Ávila Dde L, Araújo GR, Silva M, Miranda PH, Diniz MF, Pedrosa ML, et al. Vildagliptin ameliorates oxida- tive stress and pancreatic beta cell destruction in type 1 diabetic rats. Arch Med Res. 2013 Apr;44(3):194-202. DOI: 10.1016/j.arcmed.2013.03.004

16. Yono M, Pouresmail M, Takahashi W, Flanagan JF, Weiss RM, Latifpour J. Effect of insulin treatment on tissue size of the genitourinary tract in BB rats with spontaneously developed and streptozotocin-induced diabetes. Naunyn Schmiedebergs Arch Pharmacol. 2005 Nov;372(3):251-5. DOI: 10.1007/s00210-0050010-9

17. Groop PH, Thomas MC, Rosengård-Bärlund M, Mills V, Rönnback M, Thomas S, et al. HDL composition predicts new-onset cardiovascular disease in patients with type 1 diabetes. Diabetes Care. 2007 Oct;30(10):27067. DOI: $10.2337 / \mathrm{dc} 07-0030$

18. Raghunathan S, Tank P, Bhadada S, Patel B. Evaluation of buspirone on streptozotocin induced type 1 diabetes and its associated complications. Biomed Res Int. 2014;2014:948427. DOI: 10.1155/2014/948427

19. Cameron NE, Cotter MA. Diabetes causes an early reduction in autonomic ganglion blood flow in rats. J Diab Complic. 2001 Jul-Aug;15(4):198-202. DOI: 10.1016/S1056-8727(01)00149-0

20. Obrosova IG, Drel VR, Oltman CL, Mashtalir N, Tibrewala J, Groves JT, et al. Role of nitrosative stress in early neuropathy and vascular dysfunction in streptozotocin-diabetic rats. Am J Physiol Endocrinol Metab. 2007 Dec;293(6):E1645-55. DOI: 10.1152/ajpendo.00479.2007

21. Kiba T, Tanaka K, Numata K, Hoshino M, Misugi K, Inoue S. Ventromedial hypothalamic lesion-induced vagal hyperactivity stimulates rat pancreatic cell proliferation. Gastroenterology. 1996 Mar;110(3):885-93. DOI: 10.1053/gast.1996.v110.pm8608899 